\title{
MARCO ESCÉNICO Y ESCENOGRAFÍA EN LA NUEVA NOVELA
}

\author{
SCENIC FRAMEWORKS AND SCENERY \\ IN LA NUEVA NOVELA \\ Patricia Monarca \\ Universidad Austral de Chile. Valdivia, Chile. \\ patricia.monarca@uach.cl
}

\begin{abstract}
Resumen: La nueva novela es un texto que propone y promueve un profundo y dinámico diálogo interdisciplinario para dar cuenta de la complejidad del saber y de la diversidad de la experiencia humana. La sobreabundante referencia a saberes y quehaceres establece una compleja red de significaciones: dado que cada una de los saberes o experiencias aludidos crea su propio ámbito de significación, así como un tipo discursivo que le es propio, se crea en la obra un segundo plano de construcción de sentido mediante su contigüidad, su entrecruzamiento o su confrontación. Para estudiarlo, nos centraremos en el poema "Icthys", analizando el marco escénico y las escenografías, como mecanismos propicios para evidenciar una mutación epistémica, un cambio paradigmático de la simplicidad a la complejidad, de lo logocéntrico a lo biocéntrico. De lo letrado a lo vivido.
\end{abstract}

Palabras clave: Juan Luis Martínez, ICTHYS, disciplinas, tipos discursivos, redes de significación, construcción de sentido, mutación epistémica, desinstitucionalización de los saberes.

\begin{abstract}
La nueva novela is a text that proposes and promotes a deep and dynamic interdisciplinary dialogue to account for the complexity of knowledge and the diversity of human experience. The abundant reference to knowledge and practices establishes a complex web of meanings: since each knowledge or alluded experiences creates its own sphere of signification and discursive type that is proper, is created in the text a second level of construction of meaning by its contiguity, crosslinking or confrontation. To study it, we will focus on the poem "Icthys", analyzing the scenic setting and scenery, as enabling mechanisms to demonstrate an epistemic mutation, a paradigm shift from simplicity to complexity, from the logocentric to biocentric.
\end{abstract}

Keywords: Juan Luis Martínez, ICTHYS, disciplines, discursive types, networks of signification, construction of meaning, deinstitutionalization of knowledge.

Recibido: 10.12.2015. Aceptado: 16.05.2016. 
$L$ A NUEVA NOVELA de Juan Luis Martínez propone un profundo y dinámico diálogo interdisciplinario para dar cuenta de la complejidad del saber, de la multidimensionalidad y la diversidad de la experiencia humana.

En esta obra, la existencia de distintas formas discursivas, como la reflexión en forma de aforismos, la construcción silogística, el collage, las fotografías, los objetos, la argumentación filosófica, unidas a la ironía y el sarcasmo, como elementos constructores de un decir polivalente van dando forma - a la par que deformando- a un texto complejo, que intenta aproximarse desde su misma construcción a una mirada caleidoscópica capaz de acoger una realidad en permanente transformación.

Que esta obra transgrede modelos textuales está suficientemente claro y estudiado en profundidad (Carrasco, 1988; Merino, 1988; Monarca, 1993 y 1998; Paredes, 2000; Vásquez Rocca, 2005; Rosas Godoy, 2006; Galindo, 2007; Herrera, 2007; Suárez, 2009; Oyarce, 2012, entre otros), pero consideramos que esa transgresión es el extremo visible de un iceberg donde reside un cuestionamiento más profundo: el que subvierte el modo disciplinario y disciplinado de conocer. En otras palabras, La nueva novela, mediante la utilización de mecanismos como el collage, la pictografía o el objetualismo (Vásquez Rocca, 2006; Galindo, 2007; Herrera, 2007; Suárez, 2009), la sobreabundancia de cruces disciplinarios (Meyer, 2003), y la reescritura, nos sumerge en una macrometanoia (Nemeth-Baumgarten 1994), una mutación epistémica (Monarca, 2011).

Decimos que la obra subvierte el modo disciplinario y disciplinado de conocer, porque tanto las disciplinas como las formas discursivas asociadas a éstas conviven de manera tensional. La nueva novela nos presenta diversas herramientas disciplinarias de aproximación a la red, a veces para interrogarlas, como por ejemplo: "La Geografía" / "aífargoeG aL" (LNN: 20-21), o la "Nota 4. Fox terrier no desaparecido en la no-intersección de las no-avenidas (Gauss y Lobatchewsky)" (LNN: 125), a veces para exhibir sus insuficiencias, como en "Las metáforas" (LNN: 25), en "Tareas de poesía” ( $L N N$ : 95) o en la "nota 9: El oído" ( $L N N$ : 140), a veces para involucrarlas en relaciones aparentemente irreconciliables con otros instrumentos cognitivos, como en "Tareas de aritmética” ( $L N N$ : 45 -53), "Estructura del pensamiento político ( $L N N$ : 139) o en "Memorias de una sombra fugitiva" (LNN: 144).

La relativización de los tipos discursivos de la lógica, la aritmética, la 
física, la psicología, la literatura, la política, el discurso religioso, y sobre todo, del modelo cognitivo logocéntrico al que éstos están asociados, opera en dos planos.

Un primer plano lo constituyen las sobreabundantes representaciones de la diversidad de la experiencia humana:

-Distintos saberes disciplinarios: astronomía, matemáticas, filosofía, física, historia, geografía, metafísica, lingüística, psiquiatría, sociología, antropología, política, arqueología;

-Distintos quehaceres: teatro de sombras, trabalenguas, caza, pesca, viajes, vendajes de primeros auxilios;

-Distintos "guiones" sociales: visita al psiquiatra, fiesta de bodas, resolución de tareas escolares, proyección de sombras chinas, toma de fotografías;

-Distintas manifestaciones artísticas: pintura, poesía, música, danza, teatro, escultura, literatura en general;

-Distintos espacios geográficos y distintas épocas: Chile, Francia, Italia, Alemania, Grecia; Antigüedad, Época Moderna;

-Distintos idiomas: español, inglés, francés, alemán, italiano, latín, chino;

-Distintas opciones espirituales o religiosas: taoísmo, lamaísmo, budismo Zen, cristianismo;

-Diferentes lenguajes: verbal, matemático, gráfico, musical, lenguaje de sordomudos;

-Personajes reales: Jean Tardieu, Hitler, Napoleón, Tania Savich, Alicia Liddell, Ana Pavlova, Beethoven, Yoko Ono, Isabel Holger / Luis Martínez Villablanca; Gauss, Lobatchewsky, Miguel Serrano, Pablo Neruda, Gilles Deleuze, Francis Picabia, etc.;

-Personajes ficticios: Alicia, el Gato de Cheshire, Fantomas, Superman, Luisa Lane, Ofelia, Otello, etc.

Según Umberto Eco (1990), un texto representa "una cadena de artifcios que el destinatario debe actualizar ${ }^{1}$. El texto es una máquina perezosa que exige del lector un arduo trabajo cooperativo para colmar espacios

\footnotetext{
${ }^{1}$ Las cursivas son nuestras.
} 
de 'no dicho' o de 'ya dicho', espacios que, por así decirlo, han quedado en blanco, entonces el texto no es más que una máquina presuposicional" (Eco, 1990: 39). Y con lo 'no dicho' se refiere a lo no manifiesto en la superficie, en el plano de la expresión; pero precisamente son esos elementos no dichos los que deben actualizarse en la etapa de la actualización del contenido. Para ello, un texto requiere ciertos movimientos cooperativos, activos y conscientes, por parte del lector. Es decir, en la medida que debe ser actualizado, un texto postula a su destinatario como condición indispensable no sólo de su propia capacidad comunicativa concreta, sino también de la propia potencialidad significativa.

Múltiples medios, que van desde la elección de una determinada lengua (que obviamente excluirá a quien no la hable) y de un determinado grado de dificultad lingüística, la elección de un tipo de enciclopedia, de una determinada gama y riqueza de referencias, de un determinado patrimonio léxico y estilístico, de unas determinadas claves intertextuales, son los que un autor puede elegir para construir esa potencialidad significativa del texto. Así, por un lado, el autor presupone la competencia de su Lector Modelo y, por otro, la instituye. Un texto no sólo se apoya sobre una competencia, también contribuye a producirla. Autor Modelo y Lector Modelo, entonces, son determinado tipo de estrategia textual. El Lector Modelo es "un conjunto de condiciones de felicidad, establecidas textualmente, que deben satisfacerse para que el contenido potencial de un texto quede totalmente actualizado" (Eco, 1990: 90).

En La nueva novela la convivencia de saberes y quehaceres se produce con diferentes grados de acercamiento e interrelación (Paredes, 2000), articulando un discurso que se puede recorrer en diversas direcciones, no sólo sucesivas sino simultáneas, opuestas, contradictorias, que no admiten una sola categorización. La sobreabundancia de saberes y experiencias a que hacíamos referencia más arriba, contribuye a actualizar el texto como novela, antinovela, antipoesía, escritura automática, parodia literaria, reflexión filosófica, álbum fotográfico, ensayo... No se trata de lo uno o lo otro, sino de lo uno y lo otro.

Por otra parte, dado que cada una de las experiencias o saberes aludidos crea su propio ámbito de significación, y una tipología discursiva que le es propia, se crea en la obra de Martínez un segundo plano de significación mediante su contigüidad, su entrecruzamiento o su confrontación. 
A fin de estudiar la relación entre los contextos de significación que aporta cada disciplina, revisaremos las nociones de marco escénico y de escenografía planteadas por Dominique Maingueneau (2004), para intentar apropiarnos del modo en que opera el "diálogo" entre saberes en La nueva novela.

Maingueneau llama escena englobante al nivel de enunciación que viene del tipo de discurso social (político, religioso, periodístico, publicitario, etc.) donde se produce el enunciado que oímos o leemos. Desde esa escena el enunciado asume una finalidad comunicativa, y el interlocutor o el lector se sitúan ante él asumiendo el rol que le confiere el tipo de comunicación que se instaura dentro de ese discurso. En otras palabras, la escena englobante "define el estatus de los participantes en un cierto espacio pragmático" (2004: s/p). Si el enunciado pertenece al discurso publicitario, por ejemplo, el lector se situará ante él como un virtual "consumidor" que va a hacer caso, o no, del mensaje que le ofrece el texto.

El primer nivel escénico no es suficiente para que el destinatario asuma el rol concreto que le pone en relación con el locutor o con el sujeto enunciador que opera desde el enunciado. Para ello hay que situarse en un segundo nivel que corresponde a la escena de enunciación que se deriva del género al que pertenece el enunciado del texto. La escena genérica remite al "contrato" en función del cual se produce la interacción comunicativa entre los interlocutores dentro de una determinada "institución discursiva". Herrero ilustra el concepto de escena genérica con dos ejemplos: el género del "sermón" o de la "homilía" que pertenecen al discurso religioso, se constituyen por la palabra de un sacerdote que se dirige a los fieles durante la misa. Por otro lado, un "mitin" de campaña electoral pone en escena la palabra de un "candidato" que se dirige a unos "electores" (2006: 166).

Estos dos primeros niveles constituyen el marco escénico dentro del cual el texto adquiere un sentido.

El tercer nivel corresponde a la escenografía específica del texto, es decir, al tipo concreto de enunciación que el productor del texto ha escogido para orientar el discurso hacia la recepción y la interpretación del destinatario para producir en él un efecto determinado (identificación, emoción, sorpresa, interés, etc.). Siguiendo con el ejemplo del sermón, éste puede ser proferido adoptando una escenografía rigorista, altisonante, apocalíptica, o una escenografía de amabilidad y de comprensión del auditorio (Herrero, 2006: 167). 
Maingueneau señala que "la escenografía no es un simple marco o decorado. No se trata de que el discurso surja en el interior de un espacio ya construido -e independiente de ese mismo discurso- sino de que la enunciación, en su devenir, se esfuerza por poner progresivamente en funcionamiento su propio dispositivo de habla" (2004, s/p).

Atendiendo a las secciones anunciadas por el sumario, los lectores de La Nueva Novela activamos una serie de presuposiciones acerca del área del saber implicado (que se define de antemano como bibliográfico, "letrado") y, por consiguiente, del tipo de discurso social y del rol que nos corresponderá dentro de dicho tipo discursivo.

\begin{tabular}{|l|l|}
\hline Sección & Escena englobante: (discurso social presupuesto) \\
\hline Paratexto & Informativo \\
\hline $\begin{array}{l}\text { I Respuestas a problemas } \\
\text { de Jean Tardieu }\end{array}$ & $\begin{array}{l}\text { Filosófico o científico, de respuesta a problemas (relevantes). Más } \\
\text { concretamente, responder a los planteados por Jean Tardieu en su } \\
\text { obra Problemas y trabajos prácticos }\end{array}$ \\
\hline $\begin{array}{l}\text { II Cinco problemas para } \\
\text { Jean Tardieu }\end{array}$ & $\begin{array}{l}\text { Científico (de planteamiento de problemas matemáticos, lógicos, } \\
\text { espaciales), que demanda una respuesta del lector como solucionador } \\
\text { de los mismos }\end{array}$ \\
\hline III Tareas de aritmética & $\begin{array}{l}\text { Matemático: formulación de ejercicios de cálculo aritmético, que el } \\
\text { lector deberá realizar como "tarea" }\end{array}$ \\
\hline IV El espacio y el tiempo & Científico o filosófico, acerca de la espacialidad y la temporalidad \\
\hline V La zoología & Científico, de estudios zoológicos \\
\hline VI La literatura & Ensayístico / teórico (sobre temas literarios), o bien antología literaria \\
\hline $\begin{array}{l}\text { VII El desorden de los } \\
\text { sentidos }\end{array}$ & $\begin{array}{l}\text { Científico, sobre desórdenes quimio-sensoriales de los sentidos / } \\
\text { discurso ensayístico sobre Rimbaud y su concepto de videncia }\end{array}$ \\
\hline $\begin{array}{l}\text { Notas y Referencias } \\
\text { Enformativo: que aclare o ilustre con ejemplos algún punto de lo ya } \\
\text { expuesto }\end{array}$ \\
\hline $\begin{array}{l}\text { Exándenado: (la política) } \\
\text { condenafe (una cita que oriente la lectura de un texto) / discurso político }\end{array}$ \\
\hline
\end{tabular}

No obstante, la escena genérica introduce la ambigüedad: siembra la confusión, desarticula las expectativas del lector porque se desestabilizan e hibridan los géneros discursivos característicos de cada disciplina. El lector probablemente advertirá visos irónicos en el tratamiento de algunos temas.

Aunque en La nueva novela, mediante la hibridación, la mezcla de registros, la multimodalidad textual, el humor o la intromisión de un objeto, se produce una distancia radical del modelo discursivo (y por ende, disciplinario) anunciado en los títulos o en el marco escénico de los textos, 
no estamos, como en la antipoesía, ante una inversión satírica del modelo, sino ante construcciones que enfrentan al lector con su memoria textual y extratextual para reconocer (o desconocer) las estructuras verbales y no verbales en juego, y para instalar en esa perplejidad diversas interrogantes.

$\mathrm{Si}$, como propone Maingueneau "la escenografía legitima un enunciado que, a su vez, debe legitimarla y establecer que esa escenografía de donde las palabras provienen es justamente la escenografía requerida para enunciar de modo adecuado, según sea el caso, la política, la filosofía, la ciencia, la promoción de un cierto producto, etc." (2004, s/p) proponemos que el mecanismo textual utilizado legitima la reflexión acerca del estatus del conocimiento y la cultura.

Porque en La nueva novela, el diálogo interdisciplinario cumple un rol fundamental: el constituirse en la estrategia metodológica esencial para abordar los problemas de complejidad epistémica que plantea la realidad.

El modelo de la complejidad se sustenta en el principio dialógico, la presencia de los “opuestos", de dos logos en intercambio simultáneo, que se integran en una misma entidad. El diálogo es la interacción entre elementos que están interconectados y pueden distinguirse pero no separarse (interacción polifónica, puesto que se produce a partir de miradas inter y multidisciplinares), porque en la conexión se genera una propiedad o atributo que no existiría si tal conexión -dialogante- se interrumpiera. Sólo desde la interacción de los componentes dialógicos se recompone el todo, y permite mantener la dualidad en el seno de la unidad, asociando dos (o más) términos a la vez complementarios y antagonistas.

\section{Juego entre marco escénico y escenografías}

El texto "Icthys" se encuentra en la sección V, La Zoología ( $L N N$ : 75). El marco escénico presupuesto es, por tanto, el del discurso científico. Asimismo, el título Icthys, pez en griego, establece una línea de lectura a la que se suman los anzuelos adheridos y un prospecto publicitario con especificaciones técnicas sobre anzuelos (como numeraciones, longitudes, aperturas, gargantas, pesos, flotadores y precio de los modelos disponibles, además de la dirección del fabricante). También se menciona en este texto a Cetus y a 
Leviatán, monstruos marinos mitológicos, además de ballenas, cachalotes, pececillos, pescador.

Pero ya desde el título, convive con el anterior un discurso de índole religiosa: entre los símbolos empleados por los cristianos primitivos, el del pez es posiblemente el de mayor importancia. La referencia escrita más antigua del símbolo del pez es de Clemente de Alejandría, nacido alrededor del 150, quien recomienda a sus lectores (Paedagogus, III, xi) el grabar sus sellos con una paloma o un pez. Clemente no consideró necesario dar una explicación para esta recomendación, por lo que podemos con toda seguridad concluir que el significado de ambos símbolos era conocido. De hecho, por algunos monumentos sabemos que el símbolo del pez era conocido para los cristianos mucho antes que el famoso alejandrino naciera. En monumentos romanos tales como la Capella Greca y las Capillas del Sacramento de la catacumba de San Calixto, el pez era utilizado como un símbolo en las primeras décadas del siglo segundo.

El símbolo como tal pudo haber sido inspirado por la multiplicación milagrosa de los panes y peces o por la comida de los siete discípulos luego de la Resurrección, en las orillas del Mar de Galilea (Jn. 21: 9), pero su popularidad entre los cristianos se debió principalmente, al parecer, al famoso acróstico compuesto por las iniciales de cinco palabras griegas que forman la palabra pez (Ichthys).

Icthys (IX $\Theta \mathrm{Y} \Sigma$ ) era un símbolo secreto usado por los primeros cristianos para reconocerse, una especie de mini credo, debido al famoso acrónimo compuesto por las iniciales de cinco palabras griegas que forman la pa-

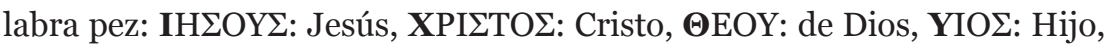
y $\mathbf{\Sigma} \Omega$ THP: Redentor. Por otra parte, los creyentes en este Ichthys místico eran ellos mismos "pequeños peces", de acuerdo con el conocido pasaje de Tertuliano (De baptismo, c. 1): "Nosotros, pequeños peces, tras la imagen de nuestro Ichthys, Jesús Cristo, nacemos en el agua" (Enciclopedia Católica online).

Esta figura del pez permitía reconocerse a los primeros cristianos sin necesidad de palabras que pudieran delatarlos. Para ello, quien deseara conocer las creencias de su interlocutor trazaba un semicírculo en la tierra. $\mathrm{Si}$ en respuesta dibujaban otro arco para completar el perfil del pez, era señal de fe compartida en las enseñanzas de Jesús. 
Otra posible lectura nos llevaría a relacionar astrológicamente al pez, y a los abundantes peces del Nuevo Testamento, con el inicio de la "era de Piscis” (Cfr. el documental Zeitgeist, por ejemplo).

En astrología una era astrológica es un período de tiempo en el que el punto vernal transita por una de las constelaciones del zodíaco, girando en el sentido de las manecillas del reloj. Tiempo que dura 2146 años y 8 meses aproximadamente. Este proceso se conoce como la precesión de los equinoccios aproximadamente cada 25.800 a 25.920 años y está dividido en 12 eras cada una de 2150 a 2160 años.

La Era de Piscis comienza en el año o, coincidiendo con el nacimiento de Jesús, y termina aproximadamente hacia 2000-2376 d.C.

Esta era representa en el zodiaco a la víctima, el mártir, el sacrificado, la relación con el cosmos y la divinidad, la oración. Durante esta era nacen 3 importantes religiones: el cristianismo, el budismo y el islam (Odle, 1998: 172).

Con Jesucristo se habría plasmado sobre la Tierra el símbolo de Piscis. Este signo zodiacal está representado por dos pececitos colocados uno en sentido contrario del otro, lo que representa la contradicción y oposición entre ciencia y religión, hombre y mujer, occidente y oriente, materia y espíritu, etc.

La Era de Piscis se caracteriza por los mártires (Jesús de Nazareth, Mahatma Gandhi, Martin Luther King, Che Guevara... podríamos nombrar las víctimas del Holocausto, los desaparecidos en dictaduras latinoamericanas...). Es una era donde la sociedad necesita o bien entregarse a algo, a una causa noble, o bien adormecerse, bien sea a través de la religión, la droga, el deporte, el cine... sumisión o desenfreno ${ }^{2}$.

El texto tiene la estructura de un salmo responsorial, es decir, un canto litúrgico, cuya parte principal es cantada por un solista y que es coreado por los fieles o el coro con un estribillo como "respuesta" (responsum) tras cada versículo o grupo de versículos. Este responsum se plantea como un eco reiterativo. El canto responsorial tiene origen en la tradición sinagogal judía y es la forma de canto más antigua de la Iglesia.

\footnotetext{
${ }^{2}$ Cfr. el artículo "De Piscis a Acuario: lo que realmente supone el cambio de era", en www.elblogalternativo.com
} 
La voz del "solista" pide confrontar una serie de textos, citados según las abreviaturas de los libros del Antiguo Testamento:

Nb. XVI, 31: Números 16, 31 (Nb, tal como aparece en la cita de $L a$ nueva novela, corresponde al francés "Nombres"): "Y aconteció que cuando cesó él de hablar todas estas palabras, se abrió la tierra que estaba debajo de ellos".

Is. V, 14: Isaías 5, 14: "Por eso ensanchó su interior el Seol, y sin medida extendió su boca; y allá descenderá la gloria de ellos, y su multitud, y su fausto, y el que en él se regocijaba"

La Encyclopædia Britannica comenta con respecto a she'ol:

El She'ol estaba situado en alguna parte debajo de la tierra. [...] La condición de los muertos no era ni de dolor ni de placer. Tampoco se asociaba con el She'ol la recompensa para los justos ni el castigo para los inicuos. Lo mismo buenos que malos, tiranos que santos, reyes que huérfanos, israelitas que gentiles, todos dormían juntos sin conciencia los unos de los otros (1971, tomo XI: 276).

Dt. XI, 6: Deuteronomio 11, 6: "y lo que hizo con Datán y Abiram, hijos de Eliab hijo de Rubén; cómo abrió su boca la tierra, y los tragó con sus familias, sus tiendas, y todo su ganado, en medio de todo Israel".

Ps. Cv. Dei, 17: De Civitate Dei 17: El tratado "La ciudad de Dios" a que hace referencia esta abreviatura, no está incluido en la Biblia. La ciudad de Dios (cuyo título latino original es De Civitate Dei contra paganos, es decir La ciudad de Dios contra los paganos) es una obra en 22 libros de Agustín de Hipona que fue escrita durante su vejez y a lo largo de quince años, entre el 412 y el 426.

En esta apología del cristianismo, Agustín toma el amor como punto de partida de una interpretación cristiana de la historia que tendrá enorme repercusión en los siglos venideros:

Dos amores fundaron, pues, dos ciudades, a saber: el amor propio hasta el desprecio de Dios, la terrena, y el amor de Dios hasta el desprecio de sí propio, la celestial (La ciudad de Dios, XVII, 115).

El acontecer histórico está determinado por el designio de Dios, que ordenó el curso de los tiempos y que se desarrolla como una lucha entre 
dos géneros distintos de sociedad (simbolizados por dos ciudades, Roma y Jerusalén): la de los que viven según la carne, paganos y amantes de sí mismos y la de los que viven según el espíritu, cristianos y amantes de Dios.

Ambas ciudades subsisten y se dan juntas en el mismo devenir histórico, pero sólo la ciudad de Dios, como ideal y fin (télos) de la historia, conseguirá triunfar e imponer la paz perpetua. Roma sucumbió a causa de su paganismo y alejamiento de Dios.

Is. XXIV, 11: Isaías 24, 11: Hay clamor por vino en las calles, toda alegría se convierte en tinieblas, desterrado está el júbilo de la tierra.

Zenaida Suárez (2009) concluye su documentado análisis de este texto -centrado en el estudio de la objetualidad "vulnerable" de los anzueloscon la siguiente interpretación:

Sobra decir que La Nueva Novela a través de los pasajes que hemos leído, denuncia la muerte y la crueldad, y condena bajo la mano Divina los actos cometidos por aquellos falsos dioses que viven en la civitas terrena; convertidos en el Leviatán.

El anzuelo, ahora sí, toma la forma simbólica de una atadura, de un poder del que es imposible soltarse y "el sublime pescador [...] Cristo de la mano rota, $[\ldots]$ " no logra atraparnos para salvarnos de la perdición última.

No obstante, tal y como podemos ver en la definición que da el Diccionario de la Real Academia Española de anzuelo, éste puede ser signo de anclaje y de liberación. Polisémico en extremo, entonces, el anzuelo de La Nueva Novela alude, tanto al desmembramiento de casas de la portada de la obra como a la apertura de las aguas del Mar Rojo, o al "¿cómo se representaría usted la falta de pescado?" de "Zoología" cuya respuesta más lógica, después de haber "leído" el anzuelo, sería: como una falta de fe (2009: 62-63).

A esta lectura queremos sumarle la disonancia que se produce entre los textos religiosos aludidos, el hermoso verso "EL SUBLIME PESCADOR ES EL CRISTO DE LA MANO ROTA / a cuyo anzuelo aún nos resistimos", y el final tan parriano, plagado de tecnicismos acerca de los anzuelos.

La escena englobante (Maingueneau, 2004) inicial, religiosa, se "desacredita" (y desacraliza) al ponerse en diálogo con el discurso publicitario. $\mathrm{Si}$ para el lector, el rol previsto por la escena genérica del salmo responsorial 
era el de pecador llamado a la conversión, o de receptor de la Palabra de Dios y parte de un coro que responde al llamado a la Salvación, con el cambio discursivo hacia lo publicitario, y el consiguiente cambio escenográfico, pasa al rol de posible consumidor: "buy it for a dollar, or make it for a dime" (cómprelo por un dólar o confecciónelo por una moneda de diez centavos)".

Esa mutua contaminación que nace del diálogo interdisciplinario nos lleva a preguntarnos, por ejemplo, si es posible "comprar" la salvación... $\mathrm{Y}$ viene a nuestra memoria el tema de la venta de indulgencias plenarias hacia la mitad del siglo XI.

El Catecismo de la Iglesia Católica ( $\left.\mathrm{N}^{\circ} 1471\right)$ dice:

La indulgencia es la remisión ante Dios de la pena temporal por los pecados, ya perdonados, en cuanto a la culpa, que un fiel dispuesto y cumpliendo determinadas condiciones consigue por mediación de la Iglesia, la cual, como administradora de la Redención, distribuye y aplica con autoridad el tesoro de las satisfacciones de Cristo y de los santos ${ }^{3}$

Es decir, no está tan alejado Martínez al sembrar tantas preguntas (¿no será simplemente su forma de signo de interrogación lo que justifica la presencia de estos anzuelos en La nueva novela?) a partir de este texto. Porque el anzuelo adherido al pie de la página invita a pensar en segundas acepciones (coloquiales) de la palabra anzuelo: morder el anzuelo es caer en una trampa, en algún atractivo o aliciente, así como echar el anzuelo implica tratar de atraer con artificios o engaños.

Muchos textos evangélicos pueden proporcionarnos redes (muy en sintonía con el tema de los peces) de lecturas múltiples. Pero una es mi predilecta: las palabras de Jesús a Simón Pedro: "Boga mar adentro" (Lucas, 5: 4). Una invitación a alejarnos del lugar seguro. Una invitación a profundizar.

La misma invitación de La nueva novela. Porque aquí no hay puntos firmes ni verdades aceptadas definitivamente. Su propósito es desarrollar un sistema de redes sin jerarquía, con la consecuente relativización de las múltiples perspectivas existentes, sin menospreciar sus aportes, y que tienda a una reorganización del saber a partir de una concepción dinámica del

${ }^{3}$ Las cursivas son nuestras. 
conocimiento. Para ello, han de ser examinados tanto los instrumentos del conocimiento como sus condiciones bioantropológicas, psicológicas, sociohistóricas y culturales de formación. Sustentándose en un pensamiento concebido como quehacer, como “obra en construcción”. La nueva novela, ya desde la portada hace tambalear nuestras certezas dejando en su lugar un espacio participativo, que entrama redes, un espacio de reflexión y producción, orientando a la vez que desorientando nuestro conocimiento acerca de las distintas problemáticas (porque no trata "temas": esboza problemáticas) enfatizando el aspecto mutacional de las mismas, y por lo tanto invitando a un grado de comprensión supratextual y supracontextual, es decir, invitando a pensar cómo pensar estas problemáticas, este texto, esta comprensión.

Para crear nuevas asociaciones, para instalar una diferencia sustancial con el saber "letrado", La nueva novela se nos presenta como texto multimodal (Kress y Van Leeuwen, 2001): a la preeminencia de lo escrito, se opondrá una propuesta del conocer "haciendo" y no sólo "leyendo": conocer a través del ensayo/error, de los caminos tentativos. Es decir, abre la posibilidad de producir sentido desde una perspectiva dinámica en que es posible afirmar, conocer, instituir y simultáneamente dudar, desnaturalizar, reconfigurar el conocimiento.

Procediendo así, a través de itinerarios exploratorios, podemos pensarnos como sujetos en un linaje de transformaciones, no como seres o esencias ya hechas sino como parte de una historia en devenir, y podemos no sólo aceptar una cuota de preguntas abiertas, de espacios no saturados, de órdenes no terminados sino también disfrutar de esa compleja urdimbre entre certeza e incerteza y aceptar la presencia de vacíos sabiendo que sólo a través de ellos puede advenir el cambio.

La nueva novela plantea la necesidad de una nueva epistemología que tome como centro del proceso al ser humano, dialogando e interactuando con los otros. No hay verdades únicas, “objetivas”, estatuidas o clausuradas. Todo puede ser revisado: el saber es abierto, flexible, holístico. Exige de todos una transformación fundamental: no podemos interpretar, entender el mundo, hablar del mundo, sin examinarnos, sin llegar a entendernos a nosotros mismos.

La nueva novela no sólo invita a la reflexión sobre el conocimiento y la cultura, sino que ensaya uno de los posibles caminos para poner ese re- 
encuentro democrático en práctica: a través de un tejido metafórico que desestructura, provoca, sugiere, despierta, remueve, conmueve e inquieta los cimientos mismos del conocimiento establecido y de la "alta cultura". A través de un diálogo entre disciplinas. A través de la deconstrucción y reconstrucción de los aprendizajes heredados, para dar lugar a una comprensión más amplia. A través de una textualidad compleja, que da cuenta de la diversidad de la experiencia humana, invitándonos a pasar del "establishment” académico a la desinstitucionalización de los saberes. Del egoísmo al amor, del control a la entrega. De lo letrado a lo vivido. Del mero saber a la sabiduría.

\section{Referencias}

Agustín de Hipona. La ciudad de Dios. Introducción de Francisco Montes de Oca. Disponible en http://historicodigital.com/download/la-ciudad-dedios.pdf.

Carrasco, I. (1988). Antipoesía y Neovanguardia. Estudios Filológicos, 23, 3553.

Catecismo de la Iglesia Católica (1997). No 1471: Qué son las indulgencias, Artículo 4: El sacramento de la Penitencia y de la Reconciliación (1422-1498), del capítulo segundo: los sacramentos de curación (1420-1421). Disponible en http://www.vatican.va/archive/catechism_sp/p2s2c2a4_sp.html

Eco, U. (1990). Lector in fabula. La cooperación interpretativa en el texto narrativo. Barcelona: Lumen.

Encyclopædia Britannica. (1971). XI Tomos. Londres: Longman.

Galindo, O. (2007). Palabras e imágenes, objetos y acciones en la postvanguardia chilena. Estudios Filológicos, 42, 109-121.

Herrera, J. (2007). La nueva novela de Juan Luis Martínez: Poesía protohipertextual en el contexto de la videósfera. Acta Literaria, 35, 9-27.

Herrero, J. (2006). Teorías de pragmática, de lingüística textual y de análisis del discurso. La Mancha: Ediciones de la Universidad de Castilla.

Kress, G. y Van Leeuwen, T. (2001). Multimodal discourse. The modes and media of contemporary communication. London: Arnold / New York: Oxford University Press.

Lucas. (1960). Evangelio. Reina-Valera: Versión Bíblica. Disponible en http:// www.bibliaenlinea.org/lucas

Maingueneau, D. (2004). ¿Situación de enunciación o situación de comunicación? Disponible en www.revista.discurso.org

Martínez, J. L. (1985). La nueva novela. Santiago: Archivo. 
Merino, R. (1988). Las expectativas de recepción en La nueva novela de Juan Luis Martínez. En R. Yamal, La poesía chilena actual (1960-1984) y la crítica (pp. 329-335). Concepción: Ediciones Lar.

Meyer, V. (2003). Poesía y física en La nueva novela de Juan Luis Martínez. Mutación disciplinaria en la poesía chilena actual. Tesis de pregrado integrada en el marco del Proyecto Fondecyt 1010747. Valdivia: Universidad Austral de Chile. Facultad de Filosofía y Humanidades.

Monarca, P. (1993). La nueva novela: la contradicción como modo de representación de la realidad. Tesis para optar al grado de Magíster en Filología, mención Literatura Hispánica. Universidad Austral de Chile . (1998). Juan Luis Martínez: el juego de las contradicciones. Santiago: DIBAM/ RIL Editores / Centro de Investigaciones Diego Barros Arana. . (2011). Mutación epistémica (Una lectura de La nueva novela desde la interdisciplinariedad y la complejidad del saber). Saarbrücken: Editorial Académica Española.

Nemeth-Baumgarten, A. (1994). Macrometanoia. Un nuevo orden. Una nueva civilización. Santiago: Editorial Sudamericana.

Odle, C. (1998). Astrología. Barcelona: Ediciones B.

Oyarce, A. (2012). Los detectives salvajes: la nueva novela de Roberto Bolaño. Narrativa terminal y de continuidad (Escritura insurreccional de un escisionista). Tesis para optar al grado de Doctor en Literatura Latinoamericana. Universidad de Concepción.

Paredes, Y. (2000). Autoría múltiple en La nueva novela de Juan Luis Martínez: la escritura anónima y plural. Tesis de grado. Valdivia: Universidad Austral de Chile.

Rosas Godoy, J. (2006). Aproximación a la estructura y estética de La nueva novela. Disponible en http://critica.cl/literatura/aproximacion-a-la-estructura-y-estetica-de-la-nueva-novela.

Suárez, Z. (2009). Objetualismo en La nueva novela y la poesía chilena de Juan Luis Martínez. Tesis para optar al grado de Magister en Literatura Hispanoamericana Contemporánea. Universidad Austral de Chile.

Vásquez Rocca, A. (2005). La reconfiguración del concepto de autor. Alteridad e Identidad en la poesía de Juan Luis Martínez. Cyber Humanitatis, Revista de la Facultad de Filosofía y Humanidades de la Universidad de Chile, 33. Disponible en http://web.uchile.cl/vignette/cyberhumanitatis/CDA/ indice/index.html.

. (2006) El giro estético de la epistemología. La ficción como conocimiento, subjetividad y texto. Aisthesis, 40, 45-61. 